\title{
Knowledge about the prevalence of Iron Deficiency Anemia and its associated risk factors in females in Saudi Arabia
}

Sultan Ahmed Almallki ${ }^{1}$, Adnan Meteb Mohamed Almezani ${ }^{2}$, Abdulaziz Ayed M Alshammari

${ }^{2}$, Ziyad Ali S Alosayfir ${ }^{2}$, Ibrahim Homoud Alshammari ${ }^{2}$, Adel Hamoud Hammad Alhammad ${ }^{2}$, Mohammed saud salem alsalem ${ }^{2}$, Shahad Mohammed Awad Alhazmi ${ }^{2}$, Faris mohammed suliman alshammari ${ }^{2}$, Nader Awad Alanazi ${ }^{1}$, Saleh Ali Saleh Kharshan AL Ghamdi ${ }^{3}$, Mona Ahmed SID Ahmed Mohammed ${ }^{4}$, Fares Ahmed S Aljohani ${ }^{5}$

Imam Muhammad ibn Saud Islamic University ${ }^{1}$, College of Medicine University of Hail ${ }^{2}$, Rawalpindi Medical College ${ }^{3}$, University of Bahr Alghazal ${ }^{4}$, College of Medicine King Saud University 5

Corresponding author: Sultan Ahmed Almallki, E-mail: drsam842@gmail.com, Phone no: +966535660600

\begin{abstract}
Background: despite the modern society and available healthy food, iron deficiency anemia is common in Saudi Arabia woman. Iron deficiency anemia is very common in women due to many risk factors like heavy menses and eating food that is not rich in iron. Knowing the prevalence of iron deficiency anemia and its associated risk factors in Saudi Arabia can provide a useful knowledge in avoiding these risk factors and improving the overall health.

Objectives: Iron deficiency anemia is increasingly common worldwide. This study aims to assess the prevalence of iron deficiency anemia and its associated risk factors in women in Saudi Arabia.

Methods: Across-sectional study on the prevalence of iron deficiency anemia was randomly carried out among women (1638 participants) in different social media platforms of Saudi Arabia during the period from February to April 2018.

Results: In $43.5 \%$ of the participants have been suffering from iron deficiency anemia, only $10.1 \%$ had a blood transfusion as a consequence of the anemia, $42.6 \%$ have sought medical help, $32.8 \%$ had heavy menses, $48.5 \%$ had a positive family history of iron deficiency anemia, only $15.4 \%$ had hypothyroidism disease, $57.2 \%$ don't eat iron rich food and only $7.9 \%$ were pregnant.

Conclusion: Our result showed that huge number of the participants was suffering from iron deficiency anemia in Saudi Arabia.
\end{abstract}

Keywords: Iron deficiency anemia, Heavy menses, Hypothyroidism.

\section{INTRODUCTION}

Anemia is a public health issue in the world affecting approximately 1.62 billion individuals or approximately a quarter of the world's population ${ }^{(1,2)}$. There are different types of anemia exist, and among these, iron deficiency anemia (IDA)which is considered the most common worldwide spread ${ }^{(3,4)}$. Iron deficiency anemia accounts for $75 \%$ of all types of anemia in the third world, affecting $30 \%$ of population ${ }^{(5)}$. IDA has reached epidemic levels in many developing countries (6) and is now the most prevalent micronutrient deficiency in the world ${ }^{(7,8)}$. Iron deficiency anemia has a negative impact on individuals, who are at risk of impaired growth, cognitive development, lower mental, motor function, poor work capacity, and generally lower quality of life ${ }^{(9)}$. Iron deficiency is caused by a prolonged period of imbalance between a person's dietary intake of iron and their body's physiological need ${ }^{(10,11)}$. Many risk factors induce an influence on an individual's iron balance, either in combination or alone ${ }^{(12)}$ ranging from sociodemographic characteristics including the individual's age, sex, marital status, level of education, income, and ethnicity to the amount, quality of the food and beverages they consume, their mental and physical health, the medication they take, any abnormalities they have, and their genetic makeup $(10,11,12)$. It is particularly true for women that if IDA is not quickly identified and treated, it has lifelong effects, including negative impacts on maternal and neonatal outcomes, and an increased risk of disability in later life ${ }^{(13)}$. In the only relevant previous study, Al Hassan ${ }^{(14)}$ reported an estimated prevalence of IDA of $64 \%$ for a sample of female university students of Saudi nationality, but their research ignored any consideration of the potential risk factors associated with IDA. 


\section{MATERIALS AND METHODS}

A cross-sectional study involving 1638 participants from Saudi Arabia was done between February-April 2018. The selected sample size for this study was randomly determined. A self-administered questionnaire was developed after a careful review of literature on the subject and it included 17 questions. The questionnaires consisted of two parts. Part one; demographical data that includes gender, age and marital status. Part two; the participants were asked whether they have been diagnosed with iron deficiency anemia or not whether they are pregnant or not, whether they received a blood transfusion or not and if they have been having some symptoms like pallor, chest pain, palpitations, shortness of breath, headache and fatigue. Participants were also asked if they have been experiencing excessive menstrual bleeding or not, if they eat iron rich food or not. They also were asked whether they have a family member who is suffering from iron deficiency anemia or not, whether they sought medical help to treat the anemia or not, whether the anemia has affected their life or not, and whether they have diabetes mellitus, hypothyroidism or stress or not. Data were collected by one method through a distribution of a survey website-link through participants living in Saudi Arabia in multiple social media platforms. Descriptive statistics were used to describe the answers of the participants in the study using numbers and percentages.
Comparing the answers for different questions within the different groups was done using Pearson chi-square test. Statistical significance was set at $\mathrm{p}<0.05$ and analysis was performed using IBM SPSS statistics, version 23 (IBM, Armonk, NY, USA).

The study was done after approval of ethical board of University of Hail.

\section{RESULT}

A total of 1638 female participants had been participated in the study. $37.7 \%$ of them were between the ages of 15 to 25 years old (Table1). More than half of the participants $57.8 \%$ are married and $42.2 \%$ are single (Table 2). Regarding patients who were diagnosed with iron deficiency anemia, almost half of the participants $43.5 \%$ were diagnosed with iron deficiency anemia of while $56.5 \%$ were not (Table 3). Regarding risk factors of iron deficiency anemia, only $7.9 \%$ of the participants were pregnant, $32.8 \%$ have been experiencing heavy menses, $57.2 \%$ don't eat food rich in iron, $48.5 \%$ have a positive family history of iron deficiency anemia and $15.4 \%$ have been diagnosed with hypothyroidism (Table 4). As regarding the consequences of iron deficiency anemia, $10.1 \%$ of the participants have received a blood transfusion (Table 5). Furthermore, $42.6 \%$ of the participants who have been diagnosed with iron deficiency anemia sought medical attention and $23 \%$ of the participants claimed that iron deficiency anemia has affected their life (Table 6).

Table (1): Age distribution of the participants

\begin{tabular}{|l|l|l|}
\hline Age & Frequency & Percent \\
\hline $15-25$ & 618 & 37.7 \\
\hline $25-35$ & 545 & 33.3 \\
\hline $35-45$ & 377 & 23 \\
\hline $45-65$ & 98 & 6 \\
\hline Total & 1638 & 100 \\
\hline
\end{tabular}

Table (2): Marital status of the participants

\begin{tabular}{|l|l|l|}
\hline Marital status & Frequency & Percent \\
\hline Single & 691 & 42.2 \\
\hline Married & 947 & 57.8 \\
\hline Total & 1638 & 100 \\
\hline
\end{tabular}

Table (3): Diagnosed with iron deficiency anemia

\begin{tabular}{|l|l|l|}
\hline Iron deficiency anemia & Frequency & Percent \\
\hline Yes & 713 & 43.5 \\
\hline No & 925 & 56.5 \\
\hline Total & 1638 & 100 \\
\hline
\end{tabular}


Table (4): Risk factors of iron deficiency anemia:

\begin{tabular}{|l|l|l|}
\hline Pregnant & Frequency & Percent \\
\hline Yes & 129 & 7.9 \\
\hline No & 1509 & 92.1 \\
\hline Total & 1638 & 100 \\
\hline Heavy menses & & \\
\hline Yes & 537 & 32.8 \\
\hline No & 1101 & 67.2 \\
\hline Total & 1638 & 100 \\
\hline Eating iron rich food & & \\
\hline Yes & 701 & 42.8 \\
\hline No & 937 & 57.2 \\
\hline Total & 1638 & 100 \\
\hline $\begin{array}{l}\text { Positive family history of iron } \\
\text { deficiency anemia }\end{array}$ & & \\
\hline Yes & 794 & 48.5 \\
\hline No & 844 & 51.1 \\
\hline Total & 1638 & 100 \\
\hline Hypothyroidism & & \\
\hline Yes & 252 & 15.4 \\
\hline No & 1386 & 84.6 \\
\hline Total & 1638 & 100 \\
\hline
\end{tabular}

Table (5): Received blood transfusion:

\begin{tabular}{|l|l|l|}
\hline Received blood transfusion & Frequency & Percent \\
\hline Yes & 164 & 10.1 \\
\hline No & 1462 & 89.9 \\
\hline Total & 1626 & 100 \\
\hline
\end{tabular}

Table (6): Participants who sought medical attention and their life has been affected

\begin{tabular}{|l|l|l|}
\hline Seek medical attention & & \\
\hline Yes & 553 & 42.6 \\
\hline No & 746 & 57.4 \\
\hline Total & 1299 & 100 \\
\hline Life has been affected & & \\
\hline Yes & 265 & 23 \\
\hline No & 886 & 77 \\
\hline Total & 1151 & 100 \\
\hline
\end{tabular}

\section{DISCUSSION}

Our study was done to explore the prevalence of iron deficiency anemia (IDA) among women in Saudi Arabia and its associated risk factors. In the present study, we found that there were a large number of women in Saudi Arabia who were suffering from IDA. Among the 1638 participants, 713 participants were suffering from IDA while 925 were not. In developing countries, the overall prevalence of anemia has been estimated to be $43 \%$, but in highly developed countries, it has been reported at a far lower level of $9 \%\left({ }^{(15)}\right.$. For example, research in an Indian setting reported that there was a prevalence of $44.0 \%$ among female university students ${ }^{(16)}$ and wide spread IDA has also been found among female students in other developing countries such as Bangladesh, where $63.3 \%$ of a female student's sample was found to have IDA (17). In contrast, in Australia; a developed country, only a $3 \%$ prevalence of IDA was found by a study using a sample of female university students ${ }^{(18)} .553$ participants asked for medical help to treat IDA while 746 did not do anything about it. As a consequence of IDA, only 164 participants received blood transfusion to correct IDA while 1462 did not. There were multiple risk factors that can cause 
IDA among the participants like being pregnant in 129 participants, suffering from heavy menses in 537 participants, having a family member who was suffering from IDA in 794 participants, don't eat iron rich food in 937 participants and suffering from hypothyroidism in 252 participants. The sample size was quite enough; limitation of this study was that we couldn't compare the results of this study with other studies as there were just few studies had been performed before our dealing with this subject.

\section{CONCLUSION}

We can conclude that iron deficiency anemia prevalence is quite large in Saudi Arabia.

Participants had a variety of risk factors that can lead to iron deficiency anemia eventually. The ministry of health and doctors from all specialties should inform, teach and support people to deal properly with deficiency anemia as well as learning how to treat and manage with risk factors that can lead to iron deficiency anemia eventually.

\section{REFERENCES}

1. World Health Organization (2008): Worldwide Prevalence of Anemia, Geneva, Switzerland.

2. Peyrin-Biroulet L, Williet $\mathbf{N}$, Cacoub $P$ (2015): on the diagnosis and treatment of iron deficiency across indications: a systematic review. Am J Clin Nutr., 102:1585-1594.

3. Anand T, Rahi M, Sharma $P$ et al. (2014): Issues in prevention of iron deficiency anemia in India. Nutrition journal., 30:764770.

4. Shander A, Goodnough LT, Javidroozi M et al. (2014): Iron deficiency anemiabridging the knowledge and practice gap. Transfus Med Rev., 28:156-166.

5. Soleimani N (2011): Relationship between anaemia, caused from the iron deficiency, and academic achievement among third grade high school female students. Science Direct. Available at: https://www.sciencedirect.com/science/article/ pii/S1877042811029041

6. Sirdah MM, Yaghi A, Yaghi AR et al. (2014): Iron deficiency anemia among kindergarten children living in the marginalized areas of Gaza Strip,
Palestine. Rev Bras Hematol

Hemoter., 36:132-138.

7. Chandyo RK, Henjum S, Ulak M et al. (2016): The prevalence of anemia and iron deficiency is more common in breastfed infants than their mothers in Bhaktapur, Nepal. Eur J Clin Nutr., 70:456-462.

8. Abu-Ouf NM, Jan MM (2015): The impact of maternal iron deficiency and iron deficiency anemia on child's health. Saudi Med J., 2:146-149.

9. Abbaspour N, Hurrell R, Kelishadi R, et al. (2014): Review on iron and its importance for human health. J Res Med Sci., 19:164-174. 10. Hurrell R, Egli I (2010): Iron bioavailability and dietary reference values. Am J Clin Nutr., 91:1461S-1467S.

11. Alquaiz AM, Gad MA, Khoja TA et al. (2013): Prevalence of anemia and associated factors in child bearing age women in Riyadh, Saudi Arabia. J Nutr Metab., 636585.

12. Al-Quaiz JM (2001): Iron deficiency anemia. A study of risk factors. Saudi Med J., 22:490-496.

13. Alquaiz AJ, Khoja TA, Alsharif A et al. (2015): Prevalence and correlates of anaemia in adolescents in Riyadh city, Kingdom of Saudi Arabia. Public Health Nutr., 18:31923200.

14. Al Hassan NN (2015): The prevalence of iron deficiency anemia in Saudi University female students. J Microsc Ultrastruct., 3:2528.

15. McLean E, Cogswell M, Egli I et al. (2009): Worldwide prevalence of anaemia, WHO Vitamin and Mineral Nutrition Information System, Public Health Nutr.,12:444-454.

16. Bano R, Ahmad N, Sharma BC et al. (2012): Nutritional anemia in the medical students. Indian Med Gaz., 1:16-18.

17. Shill KB, Karmakar P, Kibria MG et al. (2014): Prevalence of iron-deficiency anaemia among university students in Noakhali region, Bangladesh. J Health Popul Nutr., 32:103110.

18. Fayet-Moore F, Petocz P, Samman S (2014): Micronutrient status in female university students: iron, zinc, copper, selenium, vitamin B12 and folate. Nutrients, 6:5103-5116. 